\title{
Cesium Carbonate as a Heterogeneous Base Catalyst for Synthesis of 2-Aminothiophenes via Gewald Reaction
}

\author{
Farid Moeinpour, ${ }^{*}$ Raheleh Omidinia, ${ }^{\dagger}$ Nadieh Dorostkar-Ahmadi, ${ }^{\dagger}$ and Bentalhoda Khoshdeli ${ }^{\dagger}$ \\ Department of Chemistry, Islamic Azad University, Bandar Abbas Branch, Bandar Abbas 7915893144, Iran \\ *E-mail:f.moeinpour@iauba.ac.ir;.f.moeinpour@gmail.com \\ †Department of Chemistry, Islamic Azad University, Mashhad Branch, Mashhad, Iran \\ Received March 24, 2011, Accepted April 21, 2011
}

Key Words : Gewald reaction, 2-Aminothiophene, Cesium carbonate, One-pot

The synthesis of substituted 2-aminothiophenes is attractive to chemical researchers as they are important intermediates in organic synthesis and frequently used as the scaffold motif of a variety of agrochemicals, dyes, and biologically active products. ${ }^{1}$ Thus, because of their wide utility, researchers have synthesized the substituted 2aminothiophenes via efficient and convenient methods. The one-pot cyclocondensation of ketones with an activated $\alpha$ hydrogen, a cyanomethylene containing an electron-withdrawing group such as cyanoacetate and elemental sulfur in the presence of organic base, for example, morpholine, diethylamine, etc, known as the Gewald reaction, ${ }^{2}$ has been one of the most well-studied multicomponent reactions in recent years. To extend the scope of the reaction, many alterations have been made to the original Gewald's basecatalyzed, two-component combination of $\alpha$-mercapto ketones with cyanoacetate ${ }^{3}$ by varying the components ${ }^{4}$ and the conditions. ${ }^{5-7}$

However, the major problem associated with these reactions in most of the published procedures is that high catalyst loading (normally $50-100 \mathrm{~mol} \%$ or even more), and the usual long reaction time periods required for the reactions. Therefore, the development of a suitable method using additional reagents and catalysts ${ }^{6}$ for the efficient synthesis of 2-aminothiophenes in a one-pot reaction remains an attractive field to researchers. In the recent years, the solid base catalysts derived from alkali earth metallic precursors has played an important role in heterogeneous catalysis. These catalysts have several advantages over homogeneous organic basic catalysts, such as easy recovery of the catalyst, simple product isolation and reusability. Therefore, the solid base catalysts have been considered as potential alternatives to homogeneous organic basic catalysts.

In this context, we have found that the Gewald reaction occurs efficiently in the presence of cesium carbonate $\left(\mathrm{Cs}_{2} \mathrm{CO}_{3}\right)$

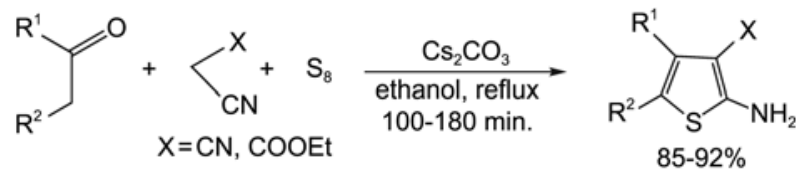

Scheme 1. Synthesis of substituted 2-aminothiophenes catalyzed by $\mathrm{Cs}_{2} \mathrm{CO}_{3}$. as a heterogeneous solid base catalyst under heating conditions by refluxing in ethanol (Scheme 1).

A variety of ketones were reacted with ethyl cyanoacetate (or malononitrile) and elemental sulfur in the presence of $\mathrm{Cs}_{2} \mathrm{CO}_{3}$ as base catalyst (Table 1). To the best of our knowledge, there is no report in the literature on the use of $\mathrm{Cs}_{2} \mathrm{CO}_{3}$ in the synthesis of 2-aminothiophenes. This reaction was studied under conventional heating conditions by refluxing in ethanol (Table 1). In all the cases, the reaction proceeded, well to produce 2-aminothiophene derivatives in good yields. All the products are known and were identified by comparison of their physical and spectroscopic data (IR, NMR) with those of authentic samples. ${ }^{3,6,7}$

To show merit of the present work in comparison with reported results in the literature, we compared, results of $\mathrm{Cs}_{2} \mathrm{CO}_{3}$ with general method of Gewald reaction, ${ }^{3}$ L-proline ${ }^{5}$ ethylenediammonium diacetate (EDDA) ${ }^{5}$ and KFalumina ${ }^{6}$ as catalysts in the reaction of cyclohexanone and ethyl cyanoacetate. As shown in Table $2, \mathrm{Cs}_{2} \mathrm{CO}_{3}$ can act as high efficiency catalyst with fast time and high yields of the obtained products.

Reusability of the catalyst was also investigated. For this purpose, the reaction of cyclohexanone and ethyl cyanoacetate was studied in refluxing ethanol. After the completion of the reaction, the catalyst was separated by simple

Table 1. $\mathrm{Cs}_{2} \mathrm{CO}_{3}$ catalyzed synthesis of 2-aminothiophenes

\begin{tabular}{ccccccc}
\hline Entry & $\mathrm{R}^{1}$ & $\mathrm{R}^{2}$ & $\mathrm{X}$ & $\begin{array}{c}\text { Yield\% } \\
\text { (Reaction } \\
\text { time, min) }\end{array}$ & $\begin{array}{c}\mathrm{mp} \\
\text { (Found) }\end{array}$ & $\begin{array}{c}\mathrm{mp} \\
\text { (Reported) }\end{array}$ \\
\hline 1 & $\mathrm{CH}_{3}$ & $\mathrm{CH}_{3}$ & COOEt & $85(180)$ & 90 & $91^{3}$ \\
2 & $\mathrm{Ph}$ & $\mathrm{CH}_{3}$ & COOEt & $92(130)$ & 94 & $93^{3}$ \\
3 & $\mathrm{Ph}$ & $\mathrm{H}$ & $\mathrm{COOEt}$ & $90(150)$ & 96 & $98^{3}$ \\
4 & $\mathrm{CH}_{3}$ & $\mathrm{COCH}_{3}$ & COOEt & $80(100)$ & 161 & $161^{3}$ \\
5 & $-\left(\mathrm{CH}_{2}\right)_{4}-$ & $\mathrm{COOEt}$ & $91(160)$ & 117 & $115^{6}$ \\
6 & $\mathrm{CH}_{3}$ & $\mathrm{CH}_{3}$ & CN & $85(120)$ & 142 & $141^{3}$ \\
7 & $-\left(\mathrm{CH}_{2}\right)_{4}-$ & $\mathrm{CN}$ & $89(140)$ & 145 & $147^{6}$ \\
8 & $\mathrm{Ph}$ & $\mathrm{H}$ & $\mathrm{CN}$ & $87(145)$ & 142 & $142^{6}$ \\
9 & $4-\mathrm{Br}-\mathrm{Ph}$ & $\mathrm{H}$ & $\mathrm{CN}$ & $88(135)$ & 192 & $190^{7}$ \\
\hline
\end{tabular}

${ }^{a}$ Isolated yields. All the products are known and were identified by comparison of their physical and spectroscopic data (IR, NMR) with those of authentic samples. 
Table 2. Comparison results of cesium carbonate with general method of Gewald reaction ${ }^{3}$, L-proline ${ }^{5}, \mathrm{KF}$-alumina ${ }^{6}$, and ethylenediammonium diacetate ${ }^{5}$ as catalysts in the reaction of cyclohexanone and ethylcyano acetate

\begin{tabular}{cllcc}
\hline Entry Condition & Catalyst & Time/min & Yield\% \\
\hline 1 & Ethanol, $70^{\circ} \mathrm{C}$ & Diethylamine & 240 & 82 \\
2 & Ethanol, $70^{\circ} \mathrm{C}$ & KF-alumina & 210 & 89 \\
3 & DMF, $60^{\circ} \mathrm{C}$ & L-Proline & 1440 & 84 \\
4 & Ionic liquid, $50{ }^{\circ} \mathrm{C}$ Ethylenediammonium & 240 & 84 \\
& & & \\
5 & Ethanol, $70^{\circ} \mathrm{C}$ & Cesium carbonate & 160 & 91 \\
\hline
\end{tabular}

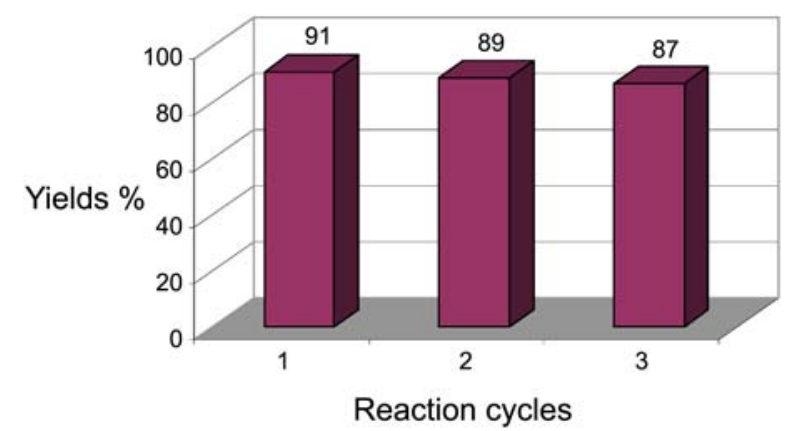

Figure 1. Recyclability of $\mathrm{Cs}_{2} \mathrm{CO}_{3}$ in the reaction of cyclohexanone, ethylcyanoacetate and elemental sulfur in refluxing ethanol.

filtration, washed with methanol, dried at $120^{\circ} \mathrm{C}$ for $2 \mathrm{~h}$ and reused for the similar reaction. As it is shown in Figure 1, the catalyst could be reused at least three times without significant loss of activity.

In conclusion, we have reported a new simple catalytic method for the synthesis of 2-aminothiophenes via Gewald reaction using $\mathrm{Cs}_{2} \mathrm{CO}_{3}$ as an efficient, reusable and green heterogeneous catalyst under heating conditions in refluxing ethanol. The catalyst could be recycled after a simple workup and reused at least three runs without appreciable reduction in its catalytic activity. Low catalyst loading, clean reaction profiles, simple experimental and workup procedures and high yields are some advantages of this protocol.

\section{Experimental Section}

All chemicals were commercially available and used without further purification. All yields refer to isolated products after purification. All the products were characterized by comparison of spectroscopic data (IR, ${ }^{1} \mathrm{H}$ NMR spectra) and melting points with authentic samples. Melting points were recorded on an electrothermal type 9100 melting point apparatus. 2-aminothiophenes were prepared according to the following general procedure:

Ketone $(1.0 \mathrm{mmol})$, nitrile $(1.0 \mathrm{mmol})$, elemental sulfur
(0.035 g, $1.1 \mathrm{mmol}), \mathrm{Cs}_{2} \mathrm{CO}_{3}(0.05 \mathrm{~g}, 0.15 \mathrm{mmol})$ in $20 \mathrm{~mL}$ ethanol, were heated at reflux for the time showed in Table 1. When the reaction was complete (Thin-Layer Chromatography), the catalyst was filtered off, solvent was removed by evaporation under reduced pressure and the crude product was purified by recrystallization in ethanol to 2aminothiophenes in high yields.

Acknowledgments. The corresponding author gratefully acknowledges the financial support from the Research Council of the Islamic Azad University, Bandar Abbas Branch.

\section{References}

1. (a) Fujita, M.; Seki, T.; Ikeda, N. Bioorg. Med. Chem. Lett. 2002, 12, 1897-1900. (b) Lutjens, H.; Zickgraf, A.; Figler, H.; Linden, J.; Olsson, R. A.; Scammells, P. J. J. Med. Chem. 2003, 46, 18701877. (c) Puterová, Z.; Krutošíková, A.; Végh, D. ARKIVOC 2010, (i), 209-246. (d) Huang, Y.; Dömling, A. Mol. Divers. 2010, DOI: 10.1007/s11030-010-9229-6. (e) Fu, T. L.; Wang, I. J. Dyes Pigments 2008, 76, 590-595. (f) Arhin, F.; Belanger, O.; Ciblat, S.; Dehbi, M.; Delorme, D.; Dietrich, E.; Dixit, D.; Lafontaine, Y.; Lehoux, D.; Liu, J.; McKay, G. A.; Moeck, G.; Reddy, R.; Rose, Y.; Srikumar, R.; Tanaka, K. S. E.; Williams, D. M.; Gros, P.; Pelletier, J.; Parr, T. R.; Far, A. R. Bioorg. Med. Chem. 2006, 14, 5812-5832.

2. Gewald, K. Chem. Heterocycl. Comp. 1976, 12, 1077-1090.

3. (a) Gewald, K. Angew. Chem. 1961, 73, 114-114. (b) Gewald, K. Chem. Berichte 1965, 98, 3571-3577. (c) Gewald, K.; Schinke, E.; Chem. Ber. 1966, 99, 94-100.

4. (a) Tormyshev, V. M.; Trukhin, D. V.; Rogozhnikova, O. Y.; Mikhalina, T. V.; Troitskaya, T. I.; Flinn, A. Synlett 2006, 25592564. (b) Gütschow, M.; Schroter, H.; Kuhnle, G.; Eger, K. Monatsh. Chem. 1996, 127, 297-303.

5. (a) Hu, Y.; Wei, P.; Huang, H.; Han, S. Q.; Ouyang, P. K. Synth. Commun. 2006, 36, 1543-1548. (b) Buchstaller, H. P.; Siebert, C. D.; Lyssy, R. H.; Frank, I.; Duran, A.; Gottschlich, R.; Noe, C. R. Monatsh. Chem. 2001, 132, 279-293. (c) Hu, Y.; Chen, Z. C.; Le, Z. G.; Zheng, Q. G. Synth. Commun. 2004, 34, 3801-3806. (d) Rossi, L.; Inesi, A. Adv. Synth. Catal. 2008, 350, 2740-2746. (e) Mojtahedi, M. M.; Abaee, S.; Mahmoodi, P.; Adib, M. Synth. Commun. 2010, 40, 2067-2074. (f) Wang, T.; Huang, X. G.; Liu, J.; Li, B.; Wu, J. J.; Chen, K. X.; Zhu, W. L.; X. Y.; Zeng, B. B. Synlett 2010, 1351-1354.

6. (a) Hesse, S.; Perspicace, E.; Kirsch, G. Tetrahedron Lett. 2007, 48, 5261-5264. (b) Hoener, A. P. F.; Henkel, B.; Gauvin, J. C. Synlett 2003, 63-66. (c) Huang, W.; Li, J.; Tang, J.; Liu, H.; Shen, J. H.; Jiang, H. L. Synth. Commun. 2005, 35, 1351-1357. (d) Zhang, H. Q.; Yang, G. C.; Chen, J. N.; Chen, Z. X. Synthesis 2004, 3055-3059. (e) Sridhar, M.; Mallikarjuna Rao, R.; Baba, N. H. K.; Kumbhare, R. M. Tetrahedron Lett. 2007, 48, 3171-3172.

7. (a) Blass, B. E. Tetrahedron 2002, 58, 9301-9320. (b) Barnes, M. D.; Haight, A. R.; Hameury, T.; McLaughlin, M. A.; Mei, J.; Tedrow, J. S.; Riva Toma, J. D. Tetrahedron 2006, 92, 1131111319. (c) Basu, B.; Das, P.; Bhuiyan, M. M. H.; Jha, S. Tetrahedron Lett. 2003, 44, 3817-3820. (d) Chhibber, M. Synlett 2004, 197-198. (e) Yang, L.; Xu, L. W.; Xia, C. G. Tetrahedron Lett. 2005, 46, 3279-3282. 